\title{
Super-twisting Sliding Mode Control of a Doubly-fed Induction Generator Based on the SVM Strategy
}

\author{
Ibrahim Yaichi1 ${ }^{1 *}$, Abdelhafid Semmah¹, Patrice Wira², Youcef Djeriri \\ 1 Department of Electrical Engineering, Faculty of Electrical Engineering, Djillali Liabes University, \\ University Campus, P. O. B. 89, Sidi Bel Abbes 022000, Algeria \\ 2 Institut de Recherche en Informatique, Mathématiques, Automatique et Signal (IRIMAS), Université de Haute-Alsace, \\ 61 Albert Camus Street, Mulhouse 68093, France \\ * Corresponding author, e-mail: ibrahimyaichi@gmail.com
}

Received: 12 January 2019, Accepted: 11 March 2019, Published online: 13 June 2019

\begin{abstract}
This paper presents direct power control (DPC) strategies using the super-twisting sliding mode control (STSMC) applied to active and reactive power control of a doubly-fed induction generator (DFIG) supplied by a space vector modulation inverter for wind turbine system. Then, a control STSMC-DPC and SVM strategies are applied. The active and reactive powers that are generated by the DFIG will be decoupled by the orientation of the stator flux and controlled by super-twisting sliding mode control. Its simulated performance is then compared with conventional sliding mode control. The test of robustness of the controllers against machine parameters uncertainty will be tackled, and the simulations will be presented. Simulation results of the proposed controller (SMC-DPC) and (STSMC-DPC) scheme are compared for various step changes in the active and reactive power. This approach super-twisting sliding mode control is validated using the Matlab/Simulink software and the results of the simulation can prove the excellent performance of this control in terms of improving the quality of the energy supplied to the electricity grid.
\end{abstract}

\section{Keywords}

renewable energy, doubly-fed induction generator (DFIG), direct power control (DPC), space vector modulation (SVM), super-twisting sliding mode control (STSMC), high-order sliding mode control (HOSMC)

\section{Introduction}

The production of renewable energy has undergone considerable development in recent years. Indeed, the modes of production based on the transformation of renewable energy for example wind, are called to be more and more used in the framework of the sustainable development [1].

The literature attests to the great interest given today to the doubly-fed induction machine (DFIM) for various applications: as a generator for wind energy or as a motor for certain industrial applications such as rolling, rail traction or propulsion maritime and aeronautical [1].

The doubly-fed induction machine has a stator similar to that of conventional three-phase machines (asynchronous cage or synchronous) usually consisting of stacked magnetic sheets provided with notches in which are inserted the windings [2].

The originality of this machine comes from the fact that the rotor differs radically because it is not composed of magnets or a squirrel cage but of three-phase winding arranged in the same way as the stator windings (wound rotor) $[3,4]$. The wound rotor comprises a three-phase winding, similar to that of the stator connected in a star and whose free end of each winding is connected to a ring and allows external connection of the windings to the rotor. This external power connection makes it possible to control the rotor quantities $[5,6]$.

The first appearance of the doubly-fed induction machine, dates from the year 1899; it is not a new structure but a new mode of supply [7].

For a wind turbine application where the use of doubly-fed induction generator (DFIG) is intense, the rotational speed of the rotor is adjusted according to the wind speed. Indeed, the DFIG allows operation in hypo synchronous and hyper synchronous generator. The interest of the variable speed for a wind turbine is to be able to work on a wide range of wind speeds, which makes it possible to draw the maximum possible power, for each wind speed $[8,9]$. 
This work will be devoted to the study and control of the DFIG-converter and turbine association. We will present modeling, the vector modulation technique SVM (space vector modulation), SMC-DPC, also STSMC-DPC control. This technique will notably present results of the simulation of the DFIG which is powered by a space vector modulation inverter.

The proposed DPC technique, based on a super-twisting sliding mode control, reduces current and power ripple. The results of the proposed controller systems simulation (STSMC-DPC) and (SMC-DPC) are compared for different step changes in the active / reactive power.

\section{DFIG model with stator flux orientation}

The general electrical state model of the induction machine obtained using Park transformation is given by [10]:

$\left\{\begin{array}{l}V_{d s}=R_{s} I_{d s}+\frac{d \varphi_{d s}}{d t}-\omega_{s} \varphi_{q s} \\ V_{q s}=R_{s} I_{q s}+\frac{d \varphi_{q s}}{d t}-\omega_{s} \varphi_{d s} \\ V_{d r}=R_{r} I_{d r}+\frac{d \varphi_{d r}}{d t}-\left(\omega_{s}-\omega_{r}\right) \varphi_{q r} \\ V_{q r}=R_{r} I_{q r}+\frac{d \varphi_{q r}}{d t}-\left(\omega_{s}-\omega_{r}\right) \varphi_{d r}\end{array}\right.$

$\left\{\begin{array}{l}\varphi_{d s}=L_{s} I_{d s}+M I_{d r} \\ \varphi_{q s}=L_{s} I_{q s}+M I_{q r} \\ \varphi_{d r}=L_{r} I_{d r}+M I_{d s} \\ \varphi_{q r}=L_{r} I_{q r}+M I_{q s}\end{array}\right.$

Active power and reactive powers can be written as Eqs. (3) and (4) [11, 12]:

$\left\{\begin{array}{l}P_{s}=V_{d s} I_{d s}+V_{q s} I_{q s} \\ Q_{s}=V_{q s} I_{d s}-V_{d s} I_{q s}\end{array}\right.$
$J \frac{d \Omega}{d t}=C_{e m}-C_{r}-f \Omega$.

Electromagnetic torque equation is given by:

$C_{e m}=\frac{3}{2} \frac{M}{L_{s}} p\left(\varphi_{q s} i_{d r}-\varphi_{d s} i_{q r}\right)$.

By applying the stator flux orientation technique to the machine model $\left(\varphi=\varphi_{d s}=\varphi_{s}\right.$ and $\left.\varphi_{q s}=0\right)$. We can write [13-15]:

$$
\left\{\begin{array}{l}
V_{d s}=R_{s} I_{d s}+\frac{d \varphi_{d s}}{d t} \\
V_{q s}=R_{s} I_{q s}-\omega_{s} \varphi_{d s} \\
V_{d r}=R_{r} I_{d r}+\frac{d \varphi_{d r}}{d t}-\left(\omega_{s}-\omega_{r}\right) \varphi_{q r} \\
V_{q r}=R_{r} I_{q r}+\frac{d \varphi_{q r}}{d t}-\left(\omega_{s}-\omega_{r}\right) \varphi_{d r}
\end{array} .\right.
$$

Still under the assumption of a constant stator flux, one can write:

$V_{d s}=0$ and $V_{q s}=V_{s}$.

The principle voltage and stator flux orientation is illustrated in Fig. 1.

$\left\{\begin{array}{l}V_{d s}=0 \\ V_{q s}=V_{s}=\omega_{s} \varphi_{s}\end{array}\right.$
$\left\{\begin{array}{l}P_{s}=-V_{s} \frac{M}{L_{s}} i_{q r} \\ Q_{s}=-V_{s} \frac{M}{L_{s}} i_{d r}+\frac{V_{s}^{2}}{L_{s} \omega_{s}}\end{array}\right.$.

\section{Sliding Mode Control}

The first order sliding mode control is a variable structure command that can change structure and commute between two values according to a very specific switching $\operatorname{logic} S(x)[16,14]$.

This command is done in two steps: the convergence towards the surface and then the sliding along it (Fig. 2).

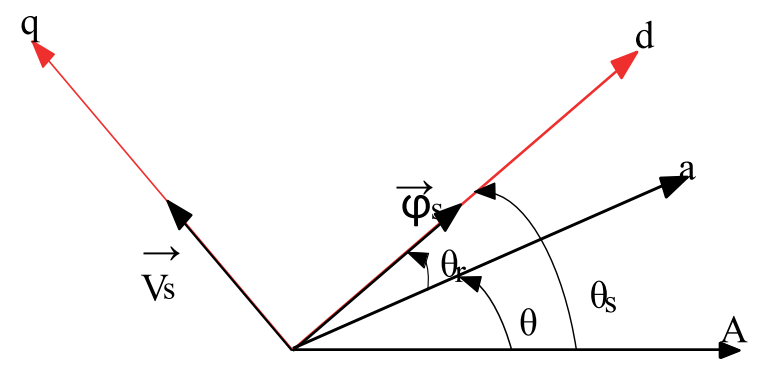

Fig. 1 Orientation of the stator flux

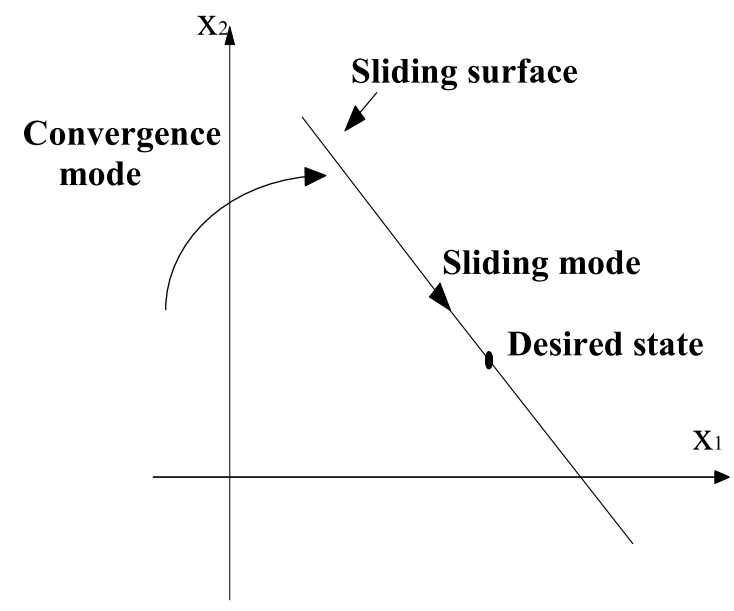

Fig. 2 Different modes of convergence 
The synthesis of the sliding mode control is done in three steps [17, 18]:

1. Choice of sliding surface.

2. Existence condition of sliding mode.

3. Determine the control law.

\subsection{Choice of the sliding surface}

For a non-linear system presented in the Eq. (10):

$\left\{\begin{array}{c}x^{n}=f(x, t)+g(x, t) u(x, t) . \\ x \in \mathfrak{R}^{n}, u \in \mathfrak{R}\end{array}\right.$.

Where $f(x, t), g(x, t)$ are two nonlinear functions continuous and uncertain supposed bounded.

We take the form of a general equation proposed by Slotine and Li [6]:

$S(x)=\left(\frac{d}{d t}+\lambda\right)^{n-1} e(x)$

$e=x-x_{d}$

$e(x)$ : error on size to be adjusted, $\lambda$ : positive coefficient, $n$ : system order, $x_{d}$ : desired size, $x$ : state variable of the ordered quantity.

\subsection{Existence condition of sliding mode}

To determine the attractiveness condition, consider the Eq. (13) Lyapunov function [20]:

$V(S)=\frac{1}{2} S^{2}$.

A necessary and sufficient condition, called attractiveness condition, for a sliding variable $S(x, t)$ to tend to 0 is that the time derivative of $V(S)$ be negative [21,22]:

$$
\dot{S} . S<0 \text {. }
$$

For a convergence in finite time, the condition (Eq. (14)) which only guarantees an asymptotic convergence towards the sliding surface is replaced by a more restrictive condition called $\eta$-attractivity and given by:

$\dot{S} . S \leq-\eta|S|, \eta>0$.

\subsection{The control law}

In our case, the method chosen is that of the equivalent control, shown schematically on Fig. 3.

The equivalent command is a continuous function that serves to maintain the variable to be controlled on the sliding surface $S=0$. It is obtained thanks to the conditions of invariance of the surface: $S=0$ and $\dot{S}=0$ [23, 24].
However, this command does not force the trajectories of the system to converge towards the sliding surface. Thus, the command $u$ is the sum of the equivalent command and a discontinuous component (Fig. 3) providing a convergence and a sliding regime [25].

$u=u_{e q}+u_{d}$

$u_{d}=-\alpha \operatorname{sign}(S)$

$\alpha$ : is a positive constant, $u_{d}$ : is the discontinuous command.

\section{Chattering}

An ideal sliding regime requires a command that can switch at an infinite frequency. Thus, during the sliding regime, the discontinuities applied to the control can cause a chattering phenomenon $[19,26]$. This is characterized by strong oscillations of the system trajectories around the sliding surface (Fig. 4). The main reasons for this phenomenon are the limitations of the actuators or switching delays at the control [30]. These switches impair the accuracy of the control and can be detrimental to the controller by causing premature deterioration of mechanical systems and a rise in temperature in electrical systems (significant loss of energy).

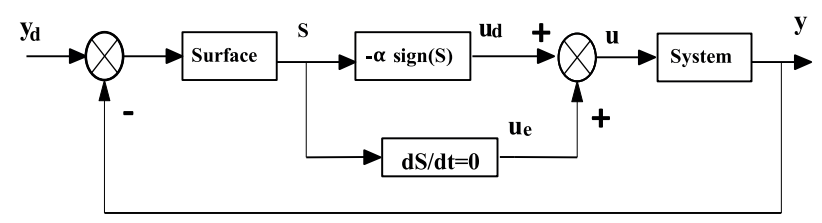

Fig. 3 Principle of the sliding control with equivalent control

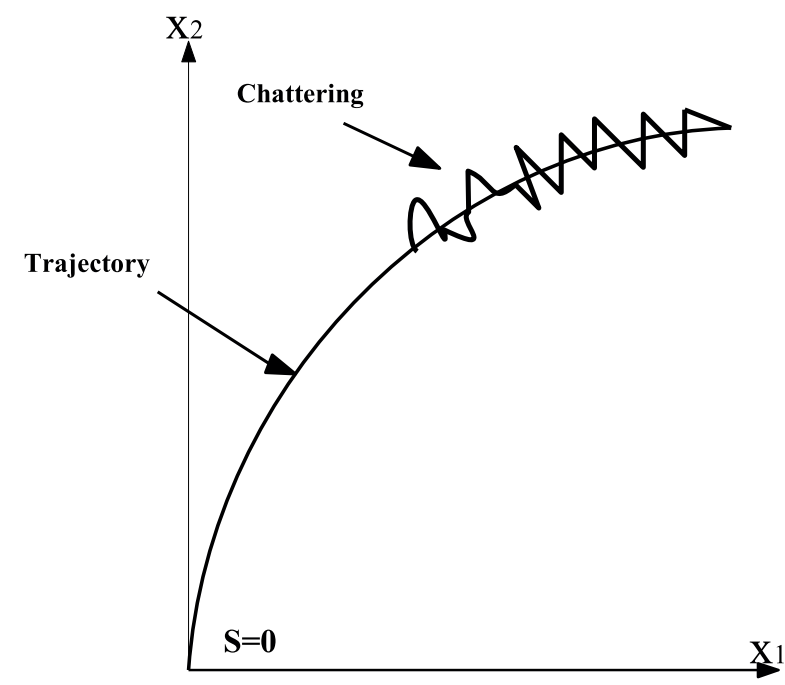

Fig. 4 The phenomenon of chattering 
In order to reduce or eliminate this phenomenon, many solutions have been proposed, such as the boundary layer solution, fuzzy sliding mode, high-order sliding mode, approach law, etc. In our work, we choose the method a super-twisting sliding mode control.

\section{High-order sliding mode}

The theory of high-order sliding mode control is an alternative to the problem of classical sliding modes [27].

In this approach, the discontinuous term no longer appears directly in the synthesized command but in one of its high derivatives, which has the merit of reducing chattering.

The high-order sliding modes have been introduced to overcome the problem of chattering while keeping the convergence properties in finite time and robustness of conventional sliding mode controls they also improve the asymptotic accuracy.

Most commands using this concept are based on the notion of homogeneity, with a particular set of coefficients (weights).

\subsection{Basic Concepts of High-Order Sliding Mode Control}

Consider an uncertain nonlinear system whose dynamics is described by:

$$
\left\{\begin{array}{c}
x^{n}=f(x, t)+g(x, t) u(x, t) \\
S=S(x, t)
\end{array}\right.
$$

$x=\left[x_{1}, \ldots \ldots x_{n}\right]^{T} \in x \subset R^{n}$ represents the state of the system.

The command $u \in U \subset R$ is a discontinuous and bounded function depending on state and time. $f$ and $g$ are sufficiently differentiable vector fields but uncertainly known.

$S$ is the sliding variable chosen to ensure finite-time convergence to the order sliding set $n$.

The sliding set of order with respect to $S(x, t)$ is defined by: $S_{n}=\left\{x \subset X: S=\dot{S}=\ldots=S^{n-1}=0\right\}$.

By abuse of language, this set is often called sliding surface of order $n$.

If the system is of relative degree $n>1$ with respect to the sliding variable, $n$-order sliding mode control will allow convergence in finite time to the surface, by forcing the system state trajectories to be confined to the sliding assembly.

\subsection{Twisting Algorithm}

In addition to the switching of the sign of the control, its amplitude is switched between two values according to the quadrant in which the state of the system is located.
The trajectory of the system in the phase plane revolves around the origin, approaching it like a spiral [28, 29].

Its expression for a system of relative degree 2 is:

$u=-r_{1} \operatorname{sign}(S)-r_{2} \operatorname{sign}(\dot{S}), \quad r_{2}>r_{1}>0$.

Under the conditions described by the inequalities (Fig. 5), the trajectory of the differential system converges at the point of equilibrium $(S, \dot{S})$ in a finite time under the following conditions:

$\left\{\begin{array}{c}\left(r_{1}-r_{2}\right) K_{m}-C_{0}>\left(r_{1}-r_{2}\right) K_{m}+C_{0} \\ \left(r_{1}+r_{2}\right) K_{m}>C_{0}\end{array}\right.$.

The homogeneity of this law of control is obvious, because its expression does not depend on the value of $S$ or $\dot{S}$, but only of their sign, which does not vary by multiplying them by $K>0$.

\subsection{Algorithm of super-twisting}

Super-twisting algorithm is an exception in a class of second order sliding mode control. This algorithm has been developed for the control of systems with relative degree equal to 1 with respect to the sliding surface [29].

Super-twisting does not use information about this can be seen as an advantage. It consists of two parts, a discontinuous part and a continuous part $u_{1}[29,31]$.

$u(t)=u_{1}(t)+u_{2}$

$\dot{u}_{1}=\left\{\begin{array}{cc}-u & \text { if }|u|>U_{M} \\ -\alpha \operatorname{sign}(S) & \text { if not }\end{array}\right.$

$u_{2}=\left\{\begin{array}{lc}-\lambda\left|S_{0}\right|^{\rho} \operatorname{sign}(S) & \text { if }|u|>S_{0} \\ -\lambda|S|^{\rho} \operatorname{sign}(S) & \text { if not }\end{array}\right.$.

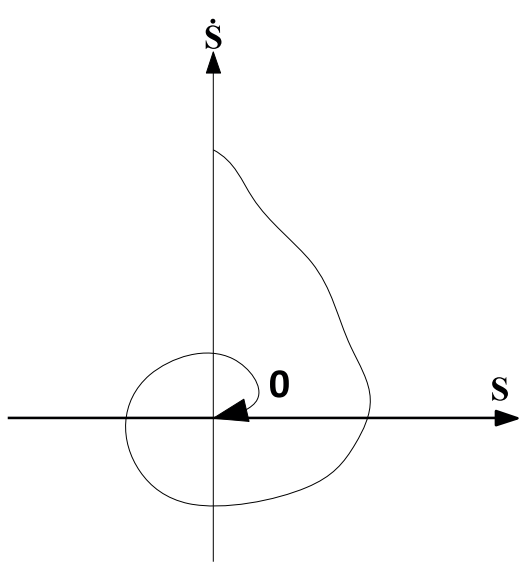

Fig. 5 Convergence of the twisting algorithm in the plane $(S, \dot{S})$ 
With $\alpha, \lambda, \rho$, checking for the following inequalities:

$\left\{\begin{array}{l}\alpha>\frac{C_{0}}{K_{m}}, \quad 0<\rho<0.5 \\ \lambda^{2}=\frac{4 C_{0} K_{M}\left(\alpha+C_{0}\right)}{K_{m}^{2} K_{m}\left(\alpha-C_{0}\right)}\end{array}\right.$

This command breaks down into an algebraic (non-dynamic) term and an integral term. We can therefore consider this algorithm as a nonlinear generalization of a proportional integral PI.

If $S_{0}=\infty$ we can simplify the algorithm:

$\left\{\begin{array}{c}u=-\lambda|S|^{\rho} \operatorname{sign}(S)+u_{1} \\ \dot{u}_{1}=-\alpha \operatorname{sign}(S)\end{array}\right.$.

By a particular choice of the model and the sliding surface, the super-twisting sliding mode control algorithm, can be formulated as an observation algorithm for the estimation of the derivative of a signal measured [31, 32].

\section{Sliding mode control of DFIG}

To control the power we take $n=1$, the expression of the control surface of the active and reactive power has the form:

$S(P)=P_{s-r e f}-P_{s}$

$S(Q)=Q_{s-r e f}-Q_{s}$

During the convergence mode, for the condition $S(P) \dot{S}(P) \leq 0$ to be satisfied, we put:

$\dot{S}(P)=-V_{s} \frac{M}{\sigma L_{s} L_{r}} V_{q r}^{n}$.

Therefore, the switching term is given by:

$V_{q r}^{n}=K V_{q r} \operatorname{sat}(S(P))$.

To check the system stability condition, the $K V_{q r}$ parameter must be positive [26].

In order to mitigate any possible exceeding of the reference voltage $V_{q r}$, it is often useful to add a voltage limiter which is expressed by:

$V_{q r}^{\lim }=V_{q r}^{\max } \operatorname{sat}(P)$.

During the convergence mode, for the condition $S(Q) \dot{S}(Q) \leq 0$ to be satisfied, we put:

$\dot{S}(Q)=-V_{s} \frac{M}{\sigma L_{s} L_{r}} V_{d r}^{n}$.

Therefore, the switching term is given by:

$V_{d r}^{n}=K V_{d r} \operatorname{sat}(S(Q))$.
To check the system stability condition, the $K V_{d r}$ parameter must be positive.

In order to mitigate any possible exceeding of the reference voltage $V_{d r}$, it is often useful to add a voltage limiter which is expressed by:

$V_{d r}^{\lim }=V_{d r}^{\max } \operatorname{sat}(Q)$.

\section{Super-twisting sliding mode control of DFIG}

A STSMC is a continuous second order sliding mode control. The STSMC control active and reactive power controllers are designed to change the $d$ and $q$ axis voltages $\left(V_{d r}, V_{q r}\right)$, respectively, as in Eqs. (34) and (35).

$$
\begin{aligned}
V_{d r}= & -\lambda\left|S_{0}(P)\right|^{\rho} \operatorname{sign}(S(P))-\alpha_{1}|S|^{\rho} \operatorname{sign}(S(P)) \\
& +\int-\alpha \operatorname{sign}(S(P)) \\
V_{q r}= & -\lambda\left|S_{0}(Q)\right|^{\rho} \operatorname{sign}(S(Q))-\alpha_{2}|S(Q)|^{\rho} \operatorname{sign}(S(Q)) \\
& +\int-\alpha \operatorname{sign}(S(Q)) .
\end{aligned}
$$

Where stator active-power error $S(P)$ and stator reactive-power error $S(Q)$ are the sliding variables and constant gains $\alpha_{1}$ and $\alpha_{2}$ verify the stability conditions.

The adequate condition for convergence to the sliding surface and for stability that the gains are large enough [29]:

$\alpha_{1}>\frac{C_{0}}{K_{m}}, \quad \alpha_{2} \geq \frac{4 C_{0} K_{M}\left(\alpha_{1}+C_{0}\right)}{K_{m}^{2} K_{m}\left(\alpha_{1}-C_{0}\right)}$.

Where $C_{0} \geq|C|$ and $K_{M} \geq K \geq K_{m}$ are the superior and inferior bounds of $C$ and $K$, respectively, in the second derivative of $y$.

$\ddot{y}=C(x, t)+K(x, t) \frac{d u}{d t}$.

In this control strategy, the active and reactive powers are regulated by two STSMC type regulators using the "SVM" algorithm.

The SVM uses a digital algorithm to obtain a control sequence of the inverter switches for generating an output voltage vector that is as close as possible to the reference voltage vector [33-35].

The block diagram of voltage vectors in the reference $(\alpha, \beta)$ is shown in Fig. 6 .

The sector is determined according to the position of the vector $V_{r_{\text {ref }}}$ in the complex plane $\left(\alpha_{r}-\beta_{r}\right)$, such that this position has the phase $\theta$ of the vector defined as Eq. (38) [36]:

$$
\theta=\arctan \left(\frac{V_{r e f(\beta)}}{V_{r e f(\alpha)}}\right) .
$$




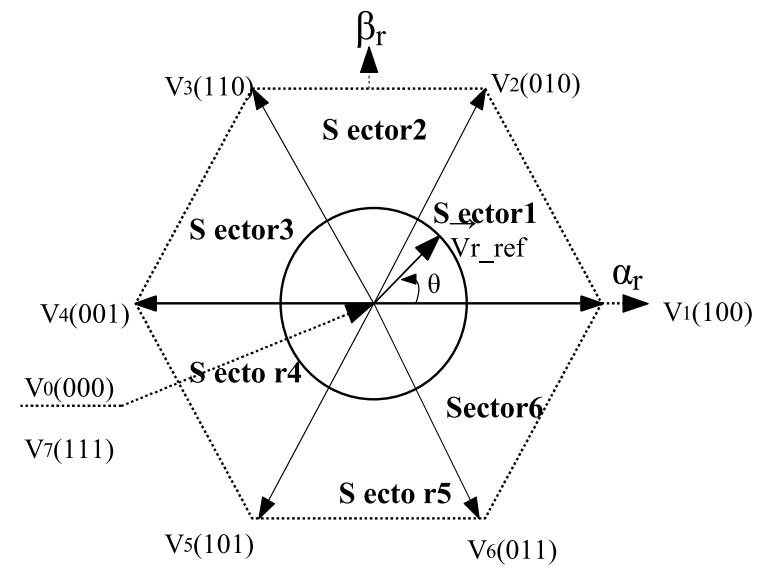

Fig. 6 Representation of the voltage vectors in the reference $(\alpha, \beta)$

A schematic diagram of the proposed STSMC-DPC for a DFIG system is shown in Fig. 7. The controller contains two sliding mode control controllers, one for the active power and another for the reactive power, as well as SVM unit. The wind turbine parameters are presented in Table 1. Table 2 presents the main parameters of the DFIG simulation model.

\section{Simulation Results}

The simulation results are shown in Figs. 8-18. The simulation is performed using Matlab/Simulink software.

\subsection{Reference tracking test}

Fig. 8 shows the wind profile used for the study of the variable speed wind turbine system. The power coefficient of the turbine is shown in Fig. 9.

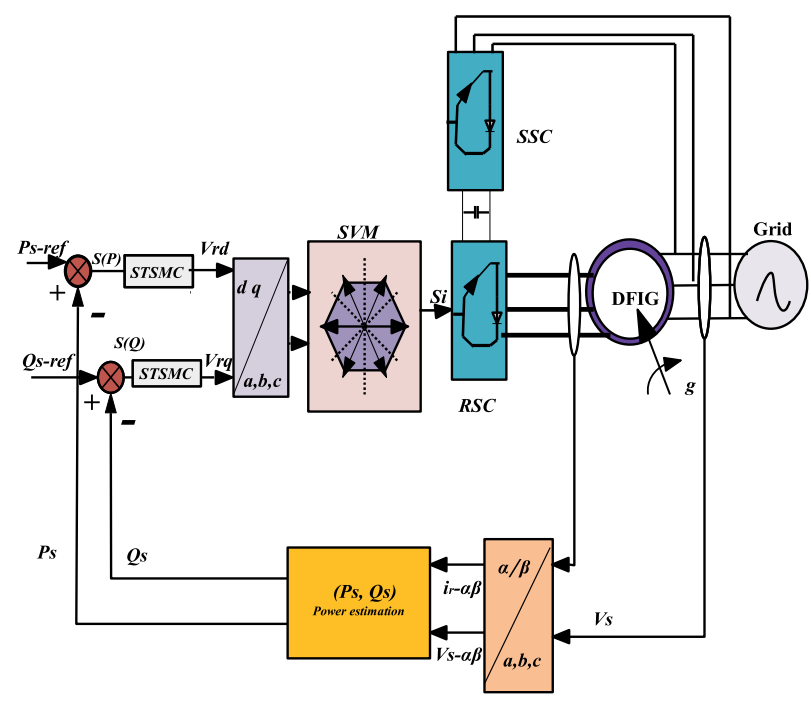

Fig. 7 Block diagram of the STSMC-DPC control
Table 1 Parameters of the wind turbine (1.5 MW) [4]

\begin{tabular}{lcc}
\hline Parameters & Unites & Values \\
\hline Number of blades & {[]} & 3 \\
The power coefficient $C p_{\max }$ & {[]} & 0.59 \\
Rotor radius $R$ & {$[\mathrm{~m}]$} & 35.25 \\
Speed multiplier gain $G$ & {[]} & 90 \\
The density of the air $\rho$ & $\mathrm{kg} / \mathrm{m}^{3}$ & 1.225 \\
Moment of total inertia $J$ & $\mathrm{Kg} \cdot \mathrm{m}^{2}$ & 1000 \\
\hline
\end{tabular}

Table 2 Doubly fed induction generator parameters [4]

\begin{tabular}{lccc}
\hline \multicolumn{1}{c}{ DFIG parameters } & \\
\hline Parameter name & Symbol & Value & Unit \\
Rated current & $P_{n}$ & 1.5 & $\mathrm{MW}$ \\
Rated DC-Link voltage & $I_{n}$ & 1900 & $\mathrm{~A}$ \\
Stator rated voltage & $U_{D C}$ & 1200 & $\mathrm{~V}$ \\
Stator rated frequency & $V_{s}$ & $398 / 690$ & $\mathrm{~V}$ \\
Rotor inductance & $f$ & 50 & $\mathrm{~Hz}$ \\
Stator inductance & $L_{r}$ & 0.0136 & $\mathrm{H}$ \\
Mutual inductance & $L_{s}$ & 0.0137 & $\mathrm{H}$ \\
Rotor resistance & $M$ & 0.0135 & $\mathrm{H}$ \\
Stator resistance & $R_{r}$ & 0.021 & $\Omega$ \\
Number of pair of poles & $R_{s}$ & 0.012 & $\Omega$ \\
\hline
\end{tabular}

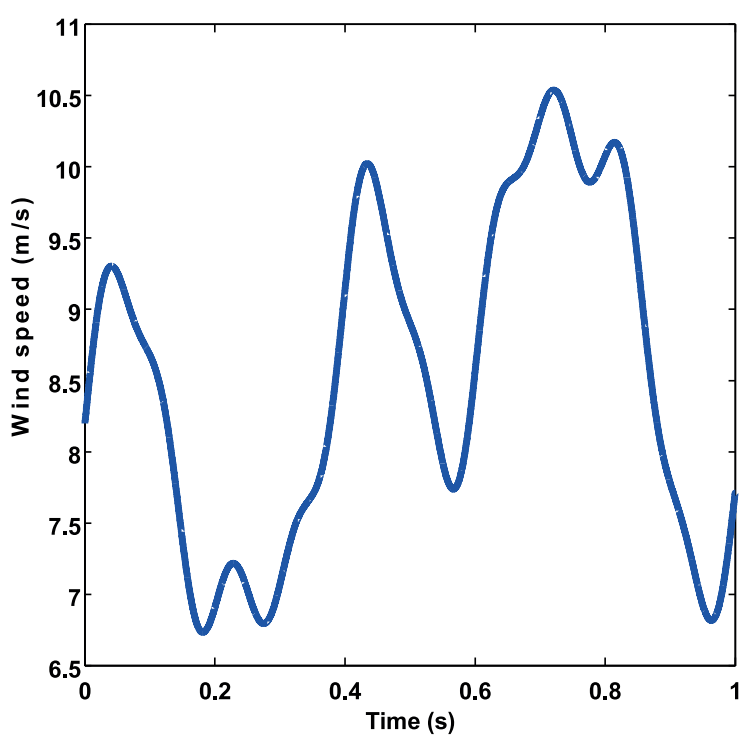

Fig. 8 Profile of the wind speed

From the result obtained in Fig. 10, the decoupling is always kept between the two powers with a very low static error.

The results illustrated by Fig. 12 show good dynamic and static performance, such as a very fast response time 


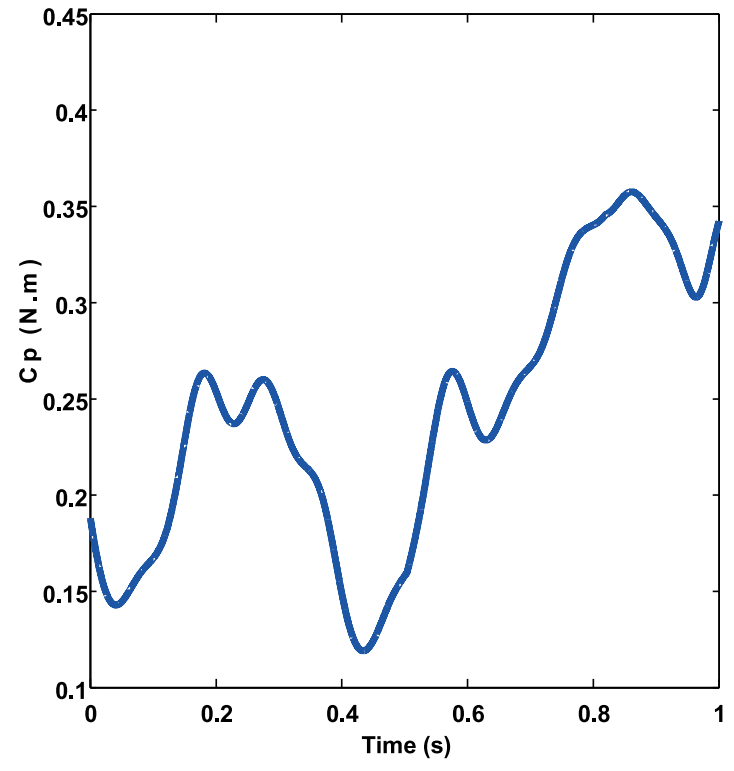

Fig. 9 Power coefficient of turbine

and no overshoot and a minimum static error for both active and reactive power. Moreover, the results obtained show that the stator and rotor currents Fig. 11 and Fig. 13 have sinusoidal shapes with less ripples, which means a good quality of energy supplied to the network.

Further tests are shown in Fig. 14 demonstrating the Total Harmonic Distortions (THD) of the stator current of the generator by using the Fast Fourier Transform (FFT) method for both control schemes SMC and STSMC. The THD of the stator current is estimated to be $0.11 \%$ for STSMC-DPC versus $1.66 \%$ for SMC-DPC.

\subsection{Robustness test}

In order to test the robustness of the sliding mode control and super-twisting sliding mode control, we will study the influence of parametric variations (rotor and stator resistance and inductances). The robustness of the two preceding techniques is tested with a simultaneous variation of $100 \%$ rotor resistance $(2 * R r)$ and stator $(2 * R s)$ and $-20 \%$ of the inductances ( $L m, L s$ and $L r$ ).

From the results obtained, it can be concluded that STSMC-DPC control (Fig. 15) has a solid robustness in the presence of the parametric variations of the doubly-fed induction generator with respect to the sliding mode control, the latter exhibiting a large number of oscillations at the level of power, but it still maintains the decoupling between the active and reactive power, because it is less dependent on the parameters of the machine. In addition, the results obtained show that the stator and rotor currents shown in Fig. 17 have sinusoidal shapes that are less

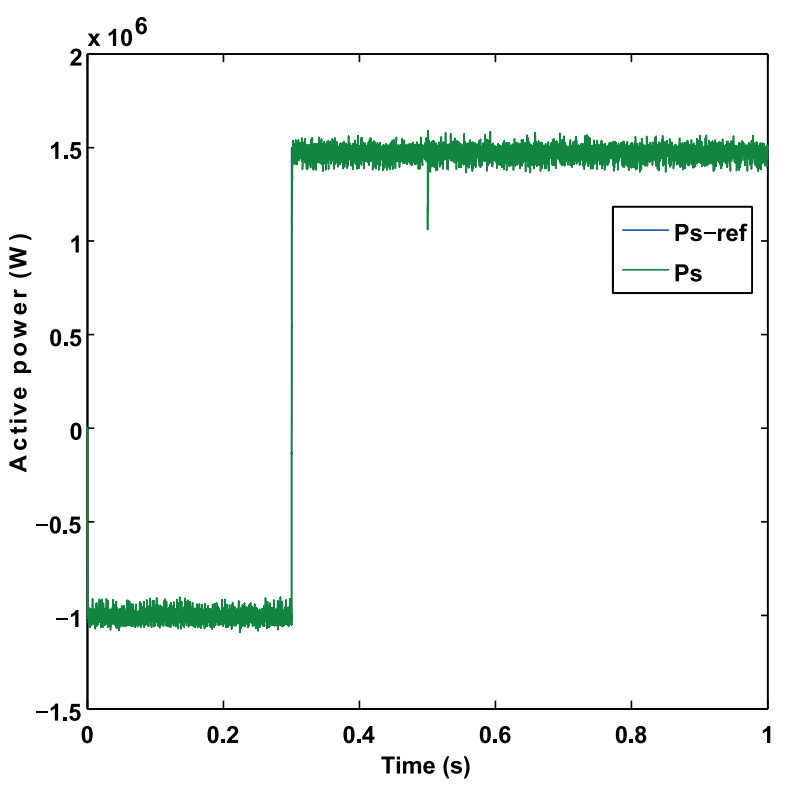

(a)

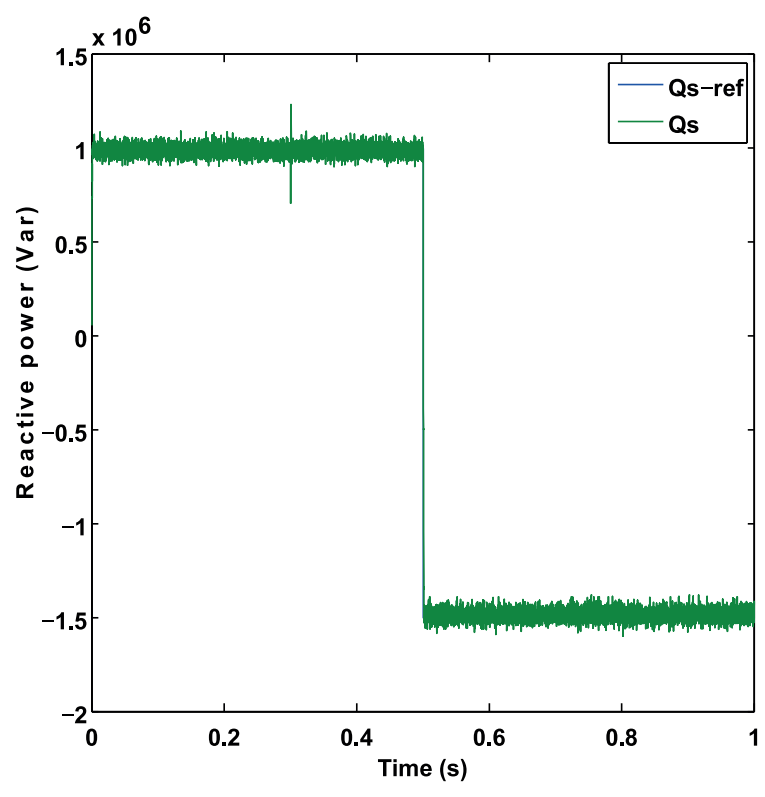

(b)

Fig. 10 SMC-DPC ((a): Active power (b): Reactive power)

corrugated compared to Fig. 16, which means a good quality of energy supplied to the network.

From the simulation results obtained in Fig. 18. The STSMC-DPC control reduces THD (harmonic distortion rate) down to $0.14 \%$ compared to the conventional SMC-DPC where THD is $2.50 \%$ by alleviating the chattering phenomenon.

The performance of the STSMC-DPC results in the maintenance of a perfect power decoupling and a net reduction of the chattering for the different parameters. 


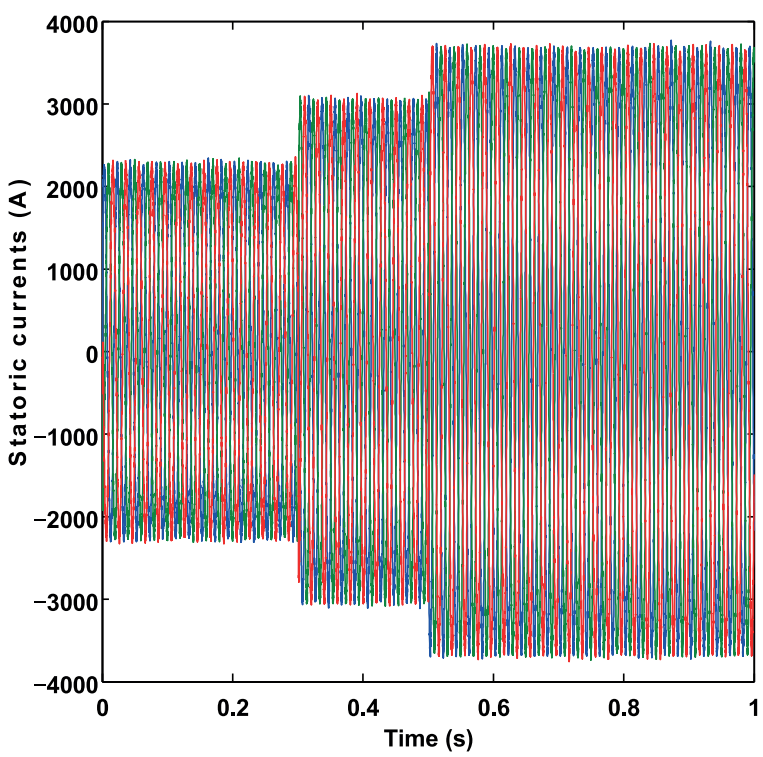

(a)

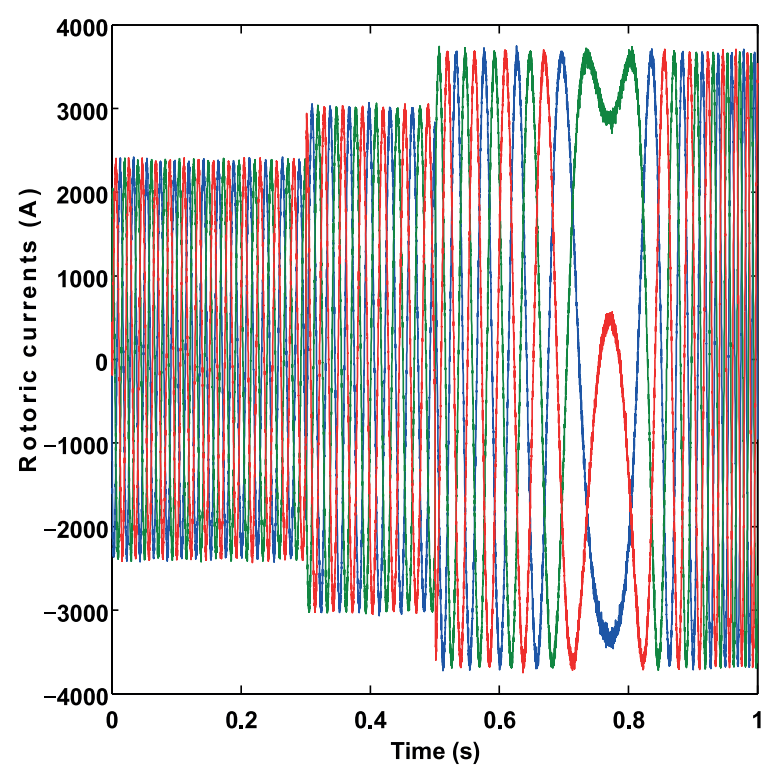

(b)

Fig. 11 SMC-DPC ((a): Stator currents, (b): Rotor currents)

On the basis of the results obtained, it can be concluded that the robust STSMC-DPC control method can be a solution for the stability of the wind system.

\section{Conclusion}

This paper proposes a STSMC-DPC schema for a doubly-fed induction generator system connected to the network. The system is implemented on a $1.5 \mathrm{MW}$ wind DFIG system.

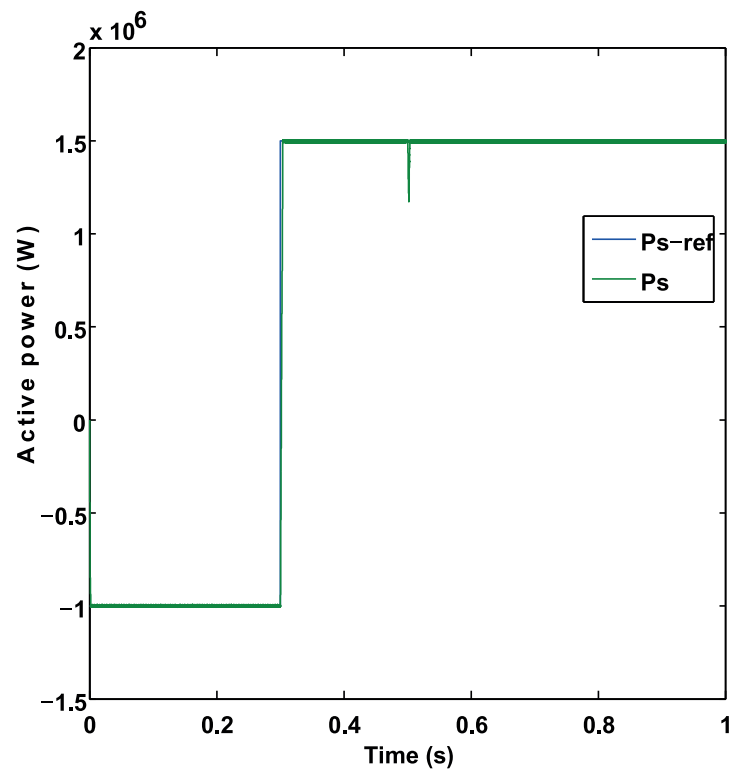

(a)

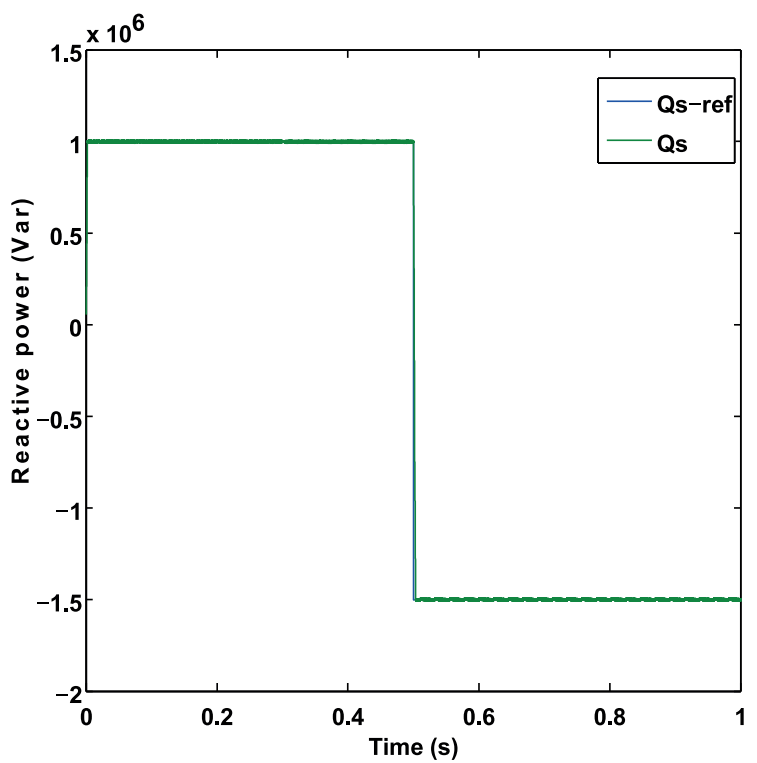

(b)

Fig. 12 STSMC-DPC ((a): Active power, (b): Reactive power)

The theory of STSMC-DPC control and its application to the doubly-fed induction generator for robust power control have been presented in this paper, where this command has a different form compared to classic sliding mode control.

The test performed by the application of the different power levels on the DFIG, clearly show that, the robustness and stability of this command, by the parametric variation test of the DFIG. 


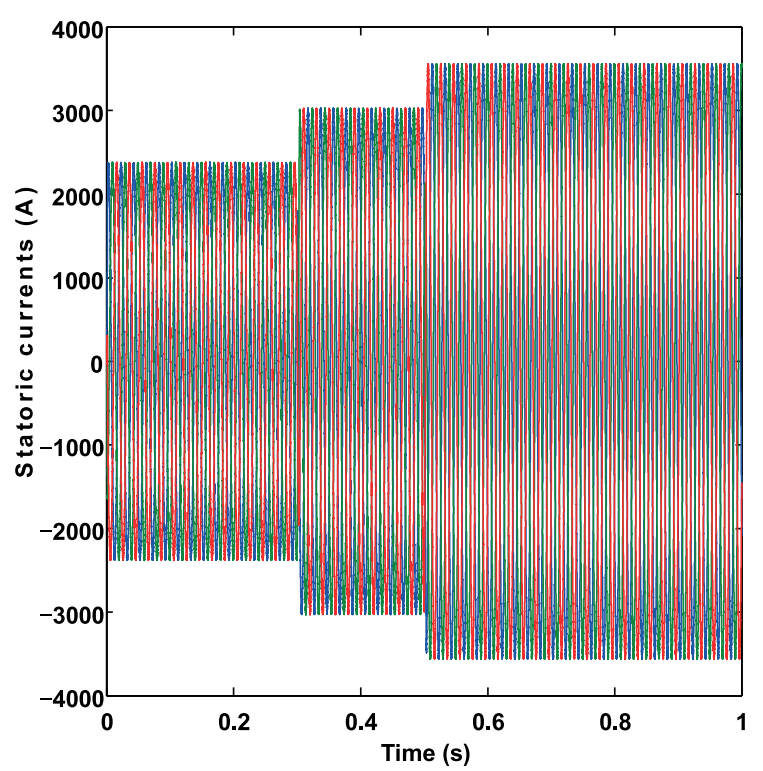

(a)

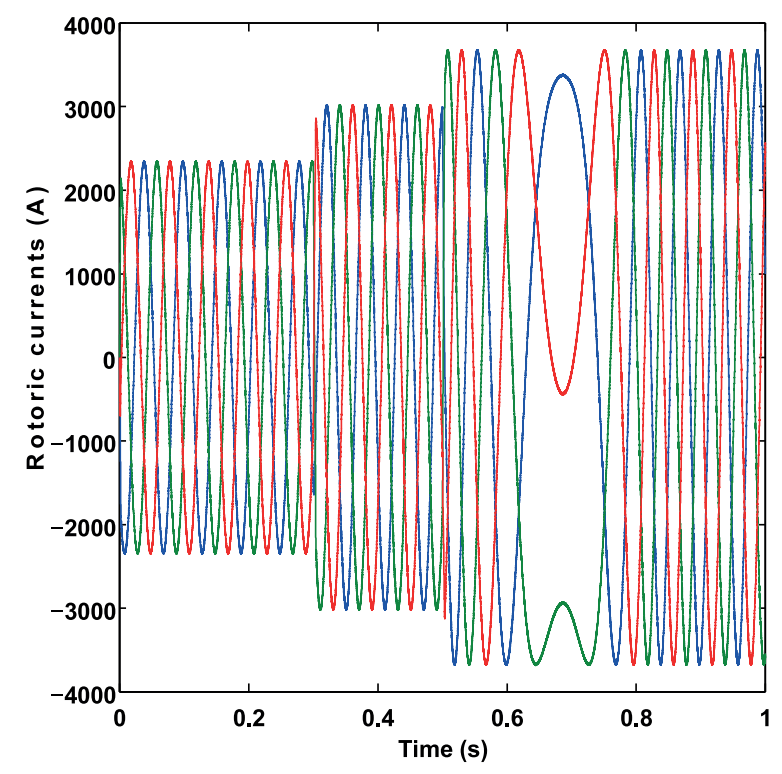

(b)

Fig. 13 STSMC-DPC ((a): Stator currents, (b): Rotor currents)

Through the system response characteristics STSMCDPC strategy, better performance is observed even in the presence of set point variations. The power continuation is without overshoot with a minimum static error. Decoupling, stability with respect to parametric variations of DFIG and convergence towards equilibrium are ensured.

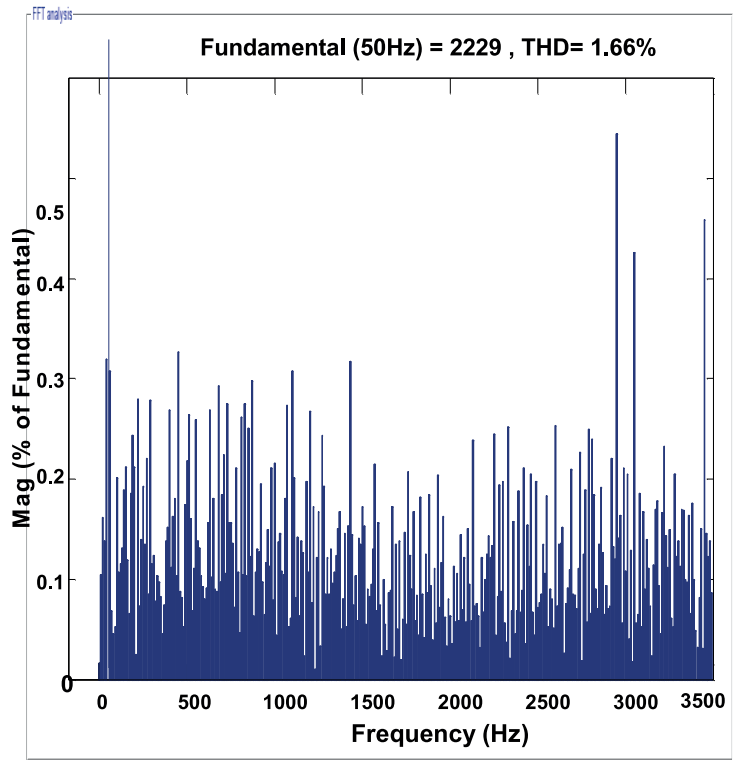

(a)

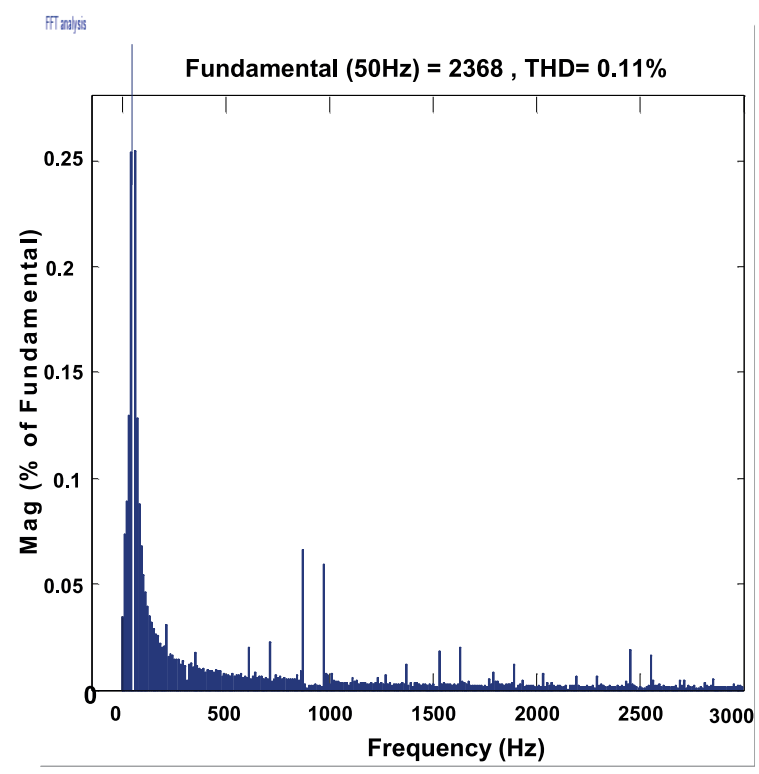

(b)

Fig. 14 Spectrum harmonic of a one-phase stator current ((a): SMC-DPC, (b): STSMC-DPC)

From the results obtained, it can be concluded that the STSMC-DPC method is a solution for the doubly-fed induction generator in order to provide a good quality of energy supplied to the grid, such as the wind energy conversion system. 


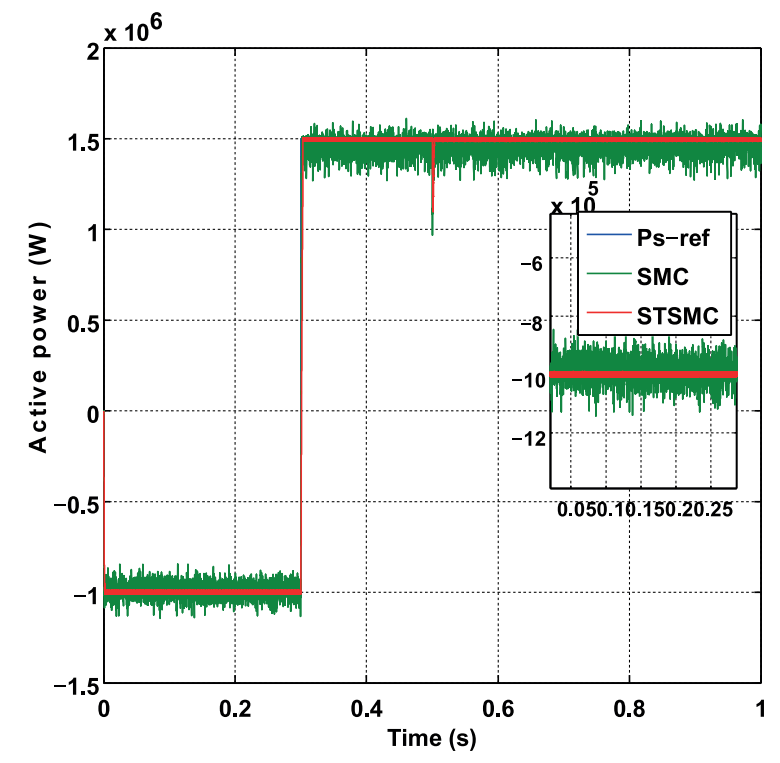

(a)

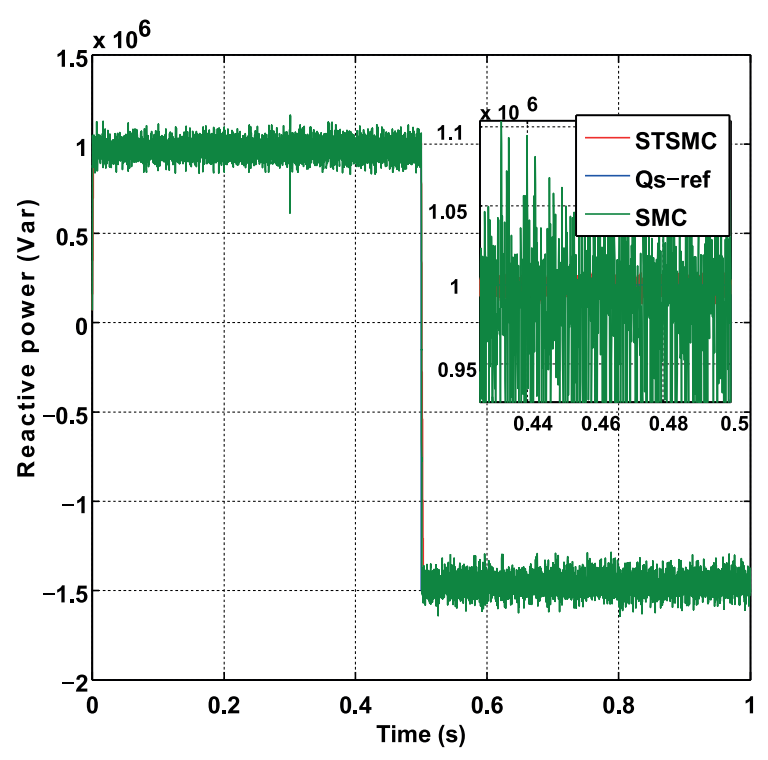

(b)

Fig. 15 SMC-DPC, STSMC-DPC ((a): Active power (b): Reactive power) (robustness test)

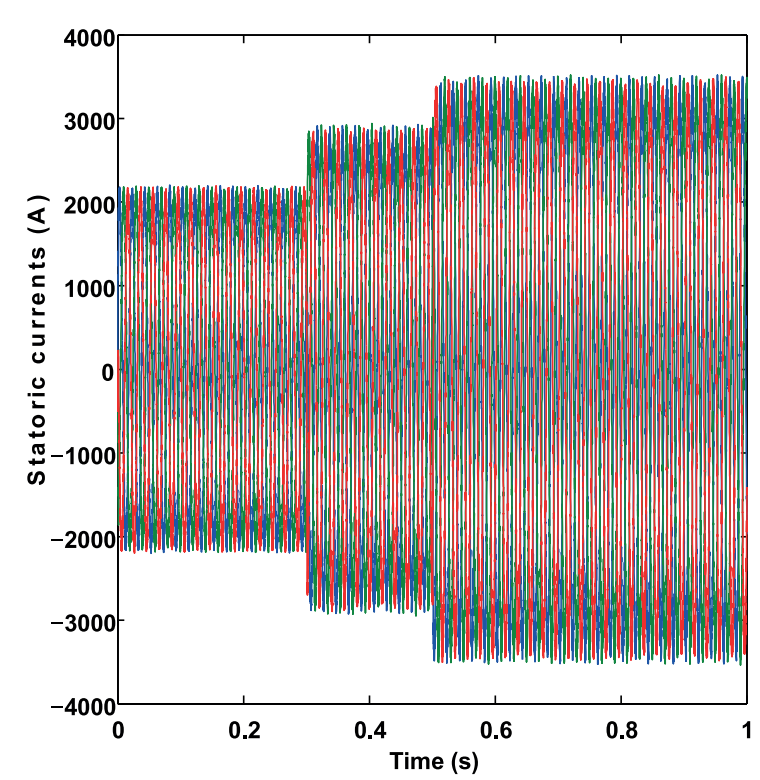

(a)

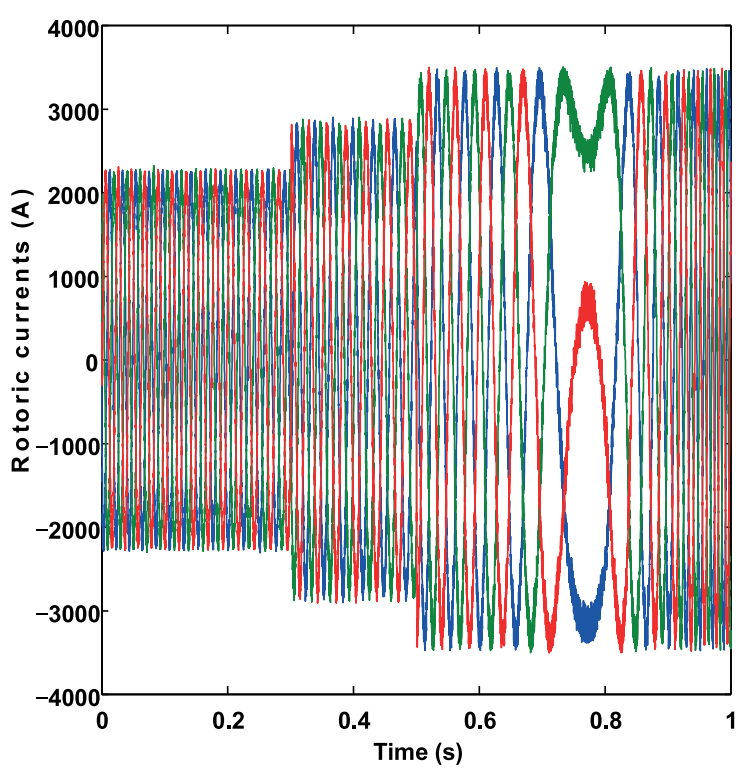

(b)

Fig. 16 SMC-DPC ((a): Stator currents, (b): Rotor currents) (robustness test) 


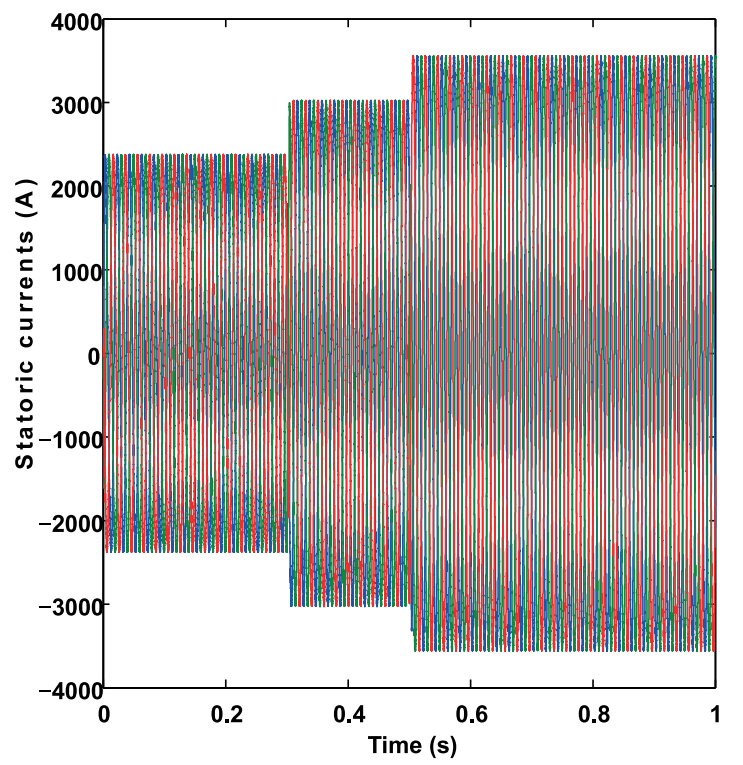

(a)

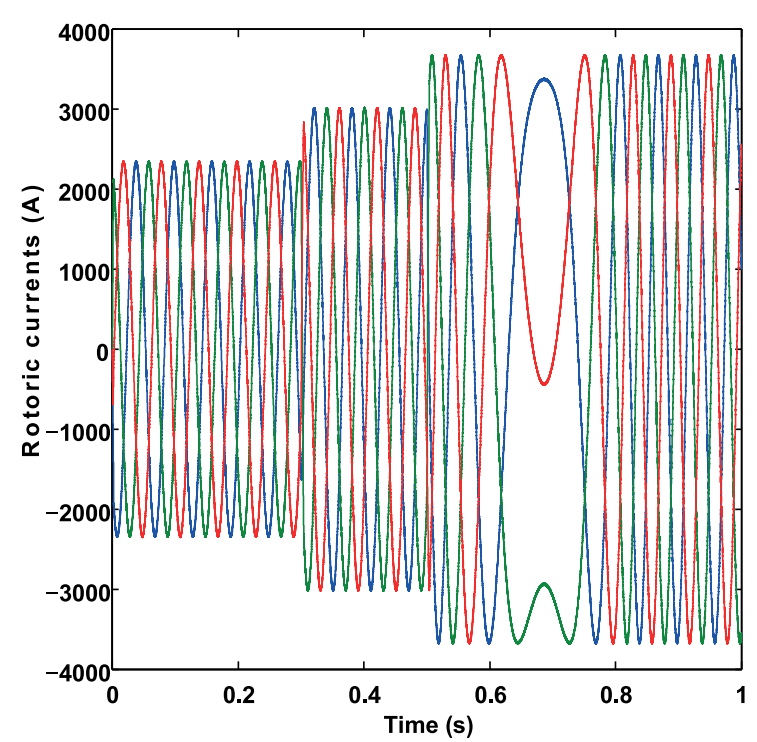

(b)

Fig. 17 STSMC-DPC ((a): Stator currents, (b): Rotor currents) (robustness test)

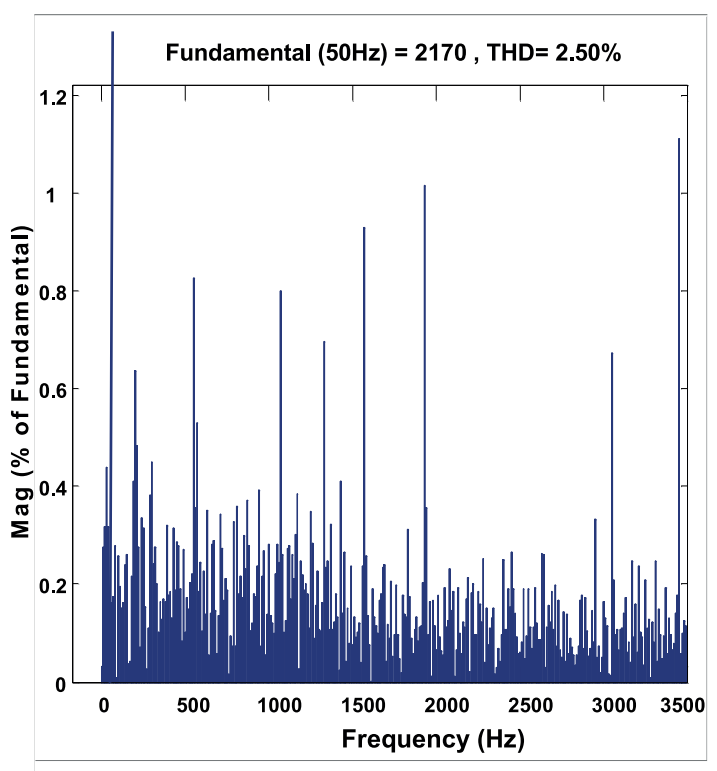

(a)

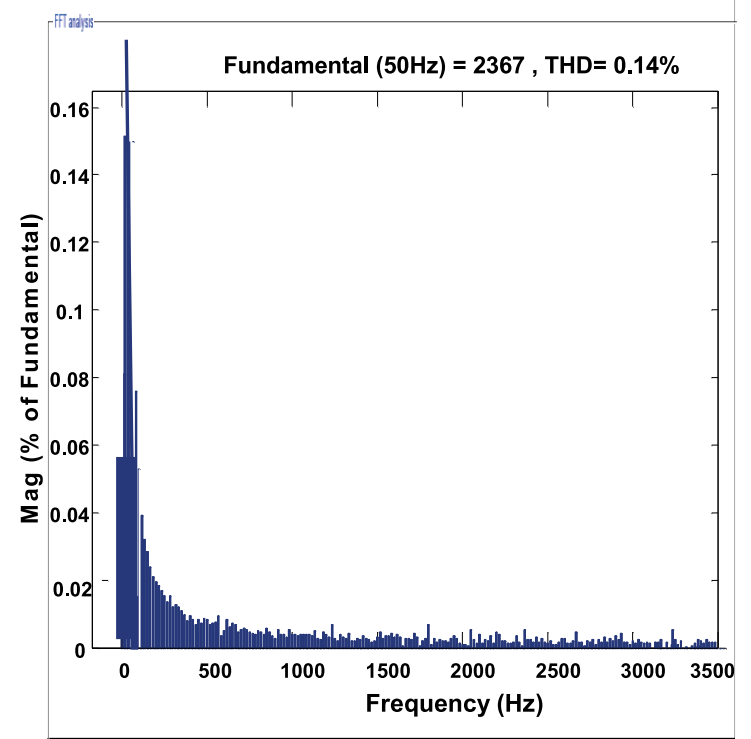

(b)

Fig. 18 Spectrum harmonic of a one-phase stator current ((a): SMC-DPC, (b): STSMC-DPC) 


\begin{tabular}{ll}
\multicolumn{2}{l}{ Nomenclature } \\
$C p$ & Power coefficient \\
$R$ & Blade radius (m) \\
$R_{s}, R_{r}$ & Stator and rotor resistances $(\Omega)$ \\
$L_{s}, L_{r}$ & Self inductance of stator and rotor $(\mathrm{H})$ \\
$M$ & Mutual magnetizing inductance. \\
$\varphi_{s}, \varphi_{r}$ & Stator and rotor flux $(\mathrm{Wb})$ \\
$C_{e m}$ & Electromagnetic torque $(\mathrm{Nm})$ \\
$v$ & Wind speed $(\mathrm{m} / \mathrm{s})$ \\
$J$ & Inertia moment of the moving element $\left(\mathrm{kgm}^{2}\right)$ \\
$\lambda$ & Ratio of the tip speed \\
$\rho$ & Air density \\
$\beta$ & Pitch angle \\
$f$ & Viscous friction and iron-loss coefficient
\end{tabular}

\section{References}

[1] Poitiers, F., Bouaouiche, T., Machmoum, M. "Advanced control of a doubly-fed induction generator for wind energy conversion", Electric Power Systems Research, 79(7), pp. 1085-1096, 2009. https://doi.org/10.1016/J.EPSR.2009.01.007

[2] Çadirci, I., Ermiş, M. "Double-output induction generator operating at subsynchronous and supersynchronous speeds: steady-state performance optimisation and wind-energy recovery", IEE Proceedings B (Electric Power Applications), 139(5), pp. 429-442, 1992.

https://doi.org/10.1049/ip-b.1992.0053

[3] Drid, S. "Contribution à la Modélisation et à la Commande Robuste d'une Machine à Induction Double Alimentée à Flux Orienté avec Optimisation de la Structure d'Alimentation: Théorie et Expérimentation" (Contribution to the Modeling and Robust Control of a Double Feed Flux Induction Machine with Optimized Feed Structure: Theory and Experimentation), $\mathrm{PhD}$ Thesis, University of Batna, Algeria, 2005. (in French)

[4] Djeriri, Y., Meroufel, A., Massoum, A., Boudjema, Z. "A Comparative Study between Field Oriented ControlStrategy and Direct Power Control Strategy for DFIG", Journal of Electric Engineering, 14(2), pp. 159-167, 2014.

[5] Vicatos, M. S., Tegopoulos, J. A. "A doubly-fed induction machine differential drive model for automobiles", IEEE Transactions on Energy Conversion, 18(2), pp. 225-230, 2003. https://doi.org/10.1109/TEC.2003.811732

[6] Slotine, J.-J. E., Li, W. "Applied Nonlinear Control", 1st ed., Prentice Hall Englewood Cliffs, NJ-USA, 1991.

[7] Abdelhafidh, M. "Stratégies de commande DTC-SVM et DPC appliquées à une MADA utilisée pour la production d'énergie éolienne" (DTC-SVM and DPC control strategies applied to an DFIG used for wind power generation), $\mathrm{PhD}$ Thesis, Ecole Nationale Polytechnique, Algiers, Algeria, 2014. (in French)

[8] Amrane, F., Chaiba, A. "A hybrid intelligent control based on DPC for grid-connected DFIG with a fixed switching frequency using MPPT strategy", In: $4^{\text {th }}$ International Conference on Electrical Engineering (ICEE), Boumerdes, Algeria, 2015, pp. 1-4. https://doi.org/10.1109/INTEE.2015.7416678

$\begin{array}{ll}p & \text { Number of pair poles } \\ G & \text { Mechanical speed multiplier } \\ \omega_{r} & \text { Electrical angular rotor speed (rad/s) } \\ \omega_{s} & \text { Synchronously rotating angular speed }(\mathrm{rad} / \mathrm{s}) \\ V_{s}, V_{r} & \text { Stator and rotor voltage }(\mathrm{V}) \\ I_{d s}, I_{q s} & \text { Direct and quadrature component of the stator } \\ & \text { currents (A) } \\ I_{d r}, I_{q r} & \text { Direct and quadrature component of the rotor } \\ g & \text { currents (A) } \\ \Omega & \text { Slip } \\ P & \text { Mechanical speed (rad/s) } \\ Q & \text { Active power (W) } \\ & \text { Reactive power (Var) }\end{array}$

[9] Kerrouche, K. D., Mezouar, A., Boumediene, L., Van den Bossche, A. "Speed sensor-less and robust power control of grid-connected wind turbine driven doubly fed induction generators based on flux orientation", The Mediterranean Journal of Measurement and Control, 12(3), pp. 606-618, 2016. [online] Available at: https://biblio.ugent.be/publication/7275252/ file/8517868.pdf [Accessed: 06 November 2018]

[10] Kahla, S., Soufi, Y., Sedraoui, M., Bechouat, M. "On-Off control based particle swarm optimization for maximum power point tracking of wind turbine equipped by DFIG connected to the grid with energy storage", International Journal of Hydrogen Energy, 40(39), pp. 13749-13758, 2015.

https://doi.org/10.1016/J.IJHYDENE.2015.05.007

[11] Wei, C., Qiao, W., Zhao, Y. "Sliding-mode oserver-based sensorless direct power control of DFIGs for wind power applications", In: IEEE Power \& Energy Society General Meeting, Colorado, USA, 2015, pp. 1-5. https://doi.org/10.1109/PESGM.2015.7286356

[12] Shah, A. P., Mehta, A. J. "Direct Power Control of DFIG using Super-Twisting Algorithm based on Second-Order Sliding Mode Control", In: $14^{\text {th }}$ International Workshop on Variable Structure Systems (VSS), Nanjing, China, 2016, pp. 136-141. https://doi.org/10.1109/VSS.2016.7506905

[13] Shang, L., Hu, J. "Sliding-Mode-Based Direct Power Control of Grid-Connected Wind-Turbine-Driven Doubly Fed Induction Generators Under Unbalanced Grid Voltage Conditions", IEEE Transactions on Energy Conversion, 27(2), pp. 362-373, 2012. https://doi.org/10.1109/TEC.2011.2180389

[14] Benbouzid, M., Beltran, B., Amirat, Y., Yao, G., Han, J., Mangel, H. "Second-order sliding mode control for DFIG-based wind turbines fault ride-through capability enhancement", ISA Transactions, 53(3), pp. 827-833, 2014. https://doi.org/10.1016/J.ISATRA.2014.01.006

[15] Wu, B., Lang, Y., Zargari, N., Kouro, S. "Power Conversion and Control of Wind Energy Systems", 1st ed., John Wiley \& Sons, New Jersey, USA, 2011. 
[16] Levant, A. "Sliding order and sliding accuracy in sliding mode control", International Journal of Control, 58(6), pp. 1247-1263, 1993. https://doi.org/10.1080/00207179308923053

[17] Levant, A. "Universal single-input-single-output (SISO) sliding-mode controllers with finite-time convergence", IEEE Transactions on Automatic Control, 46(9), pp. 1447-1451, 2001. https://doi.org/10.1109/9.948475

[18] Bartolini, G., Ferrara, A., Usai, E. "Chattering avoidance by second-order sliding mode control", IEEE Transactions on Automatic Control, 43(2), pp. 241-246, 1998. https://doi.org/10.1109/9.661074

[19] Jamoussi, K., Ouali, M., Chrifi-Alaoui, L., Benderradji, H., Hajjaji, A. E. "Robust Sliding Mode Control Using Adaptive Switching Gain for Induction Motors", International Journal of Automation and Computing, 10(4), pp. 303-311, 2013. https://doi.org/10.1007/s11633-013-0725-x

[20] Ishigame, A., Furukawa, T., Kawamoto, S., Taniguchi, T. "Sliding mode controller design based on fuzzy inference for nonlinear systems (power systems)", IEEE Transactions on Industrial Electronics, 40(1), pp. 64-70, 1993. https://doi.org/10.1109/41.184822

[21] Torchani, B., Sellami, A., Garcia, G. "Variable speed wind turbine control by discrete-time sliding mode approach", ISA Transactions, 62, pp. 81-86, 2016. https://doi.org/10.1016/J.ISATRA.2016.01.001

[22] Schmidt, I., Vincze, K., Veszprémi, K. "Vector Sliding Mode Control of Sinusoidal-Field Synchronous Servo Drive", Periodica Polytechnica Electrical Engineering, 45(1), pp. 65-77, 2001. [online] Available at: https:/pp.bme.hu/ee/article/view/976/577 [Accessed: 13 November 2018]

[23] Cupertino, F., Naso, D., Mininno, E., Turchiano, B. "Sliding-Mode Control With Double Boundary Layer for Robust Compensation of Payload Mass and Friction in Linear Motors", IEEE Transactions on Industry Applications, 45(5), pp. 1688-1696, 2009. https://doi.org/10.1109/TIA.2009.2027521

[24] Bellarbi, S., Saheb Koussa, D., Djoudi, A. "Sliding Mode Control for PMSG-based Wind Power System", Journal of Physics: Conference Series, 1081, article number: 012012, 2018. https://doi.org/10.1088/1742-6596/1081/1/012012

[25] Shehata, E. G. "Sliding mode direct power control of RSC for DFIGs driven by variable speed wind turbines", Alexandria Engineering Journal, 54(4), pp. 1067-1075, 2015. https://doi.org/10.1016/J.AEJ.2015.06.006

[26] Errami, Y., Ouassaid, M.,Cherkaoui, M., Maaroufi, M. "Sliding Mode Control Scheme of Variable Speed Wind Energy Conversion System Based on the PMSG for Utility Network Connection", In: Azar, A. T., Zhu, Q. (eds.) Advances and Applications in Sliding Mode Control systems, Studies in Computational Intelligence, 1st ed., Springer, Cham, Switzerland, pp. 167-200, 2015. https://doi.org/10.1007/978-3-319-11173-5_6
[27] Jing, Y., Sun, H., Zhang, L., Zhang, T. "Variable Speed Control of Wind Turbines Based on the Quasi-Continuous High-Order Sliding Mode Method", Energies, 10(10), article number: 1626, 2017. https://doi.org/10.3390/en10101626

[28] Şeker, M., Zergeroğlu, E., Tatlicioğlu, E. "Non-linear control of variable-speed wind turbines with permanent magnet synchronous generators: a robust backstepping approach", International Journal of Systems Science, 47(2), pp. 420-432, 2016. https://doi.org/10.1080/00207721.2013.834087

[29] Han, Y., Liu, X. "Continuous higher-order sliding mode control with time-varying gain for a class of uncertain nonlinear systems", ISA Transactions, 62, pp. 193-201, 2016. https://doi.org/10.1016/J.ISATRA.2016.02.005

[30] Kalamian, N., Verij Kazemi, M., Gholomian, S. A. "Direct Power Control of Dfig by Using Nonlinear Model Predictive Controller", Asian Journal of Control, 18(3), pp. 985-999, 2016. https://doi.org/10.1002/asjc.1170

[31] Tayebi-Haghighi, S., Piltan, F., Kim, J.-M. "Robust Composite High-Order Super-Twisting Sliding Mode Control of Robot Manipulators", Robotics, 7(1), article number: 13, 2018. https://doi.org/10.3390/robotics7010013

[32] Barambones, O. "Robust Wind Speed Estimation and Control of Variable Speed Wind Turbines", Asian Journal of Control, 21(2), pp. 856-867, 2019. https://doi.org/10.1002/asjc.1779

[33] Abosh, A. H., Zhu, Z. Q., Ren, Y. "Reduction of Torque and Flux Ripples in Space Vector Modulation-Based Direct Torque Control of Asymmetric Permanent Magnet Synchronous Machine", IEEE Transactions on Power Electronics, 32(4), pp. 2976-2986, 2017. https://doi.org/10.1109/TPEL.2016.2581026

[34] Swierczynski, D., Kazmierkowski, M. P. "Direct torque control of permanent magnet synchronous motor (PMSM) using space vector modulation (DTC-SVM)-simulation and experimental results", In: $28^{\text {th }}$ Annual Conference of the Industrial Electronics Society (IECON 02), Sevilla, Spain, 2002, pp. 751-755. https://doi.org/10.1109/IECON.2002.1187601

[35] Wang, X., Wang, Z., Cheng, M., Hu, Y. "Remedial Strategies of T-NPC Three-Level Asymmetric Six-Phase PMSM Drives Based on SVM-DTC", IEEE Transactions on Industrial Electronics, 64(9), pp. 6841-6853, 2017. https://doi.org/10.1109/TIE.2017.2682796

[36] Yang, Y., Hunag, R., Yu, Y., Wang, S. "Direct torque control of permanent magnet synchronous motor based on space vector modulation control", In: $8^{\text {th }}$ International Power Electronics and Motion Control Conference (IPEMC-ECCE Asia), Hefei, China, 2016, pp. $1818-1821$ https://doi.org/10.1109/IPEMC.2016.7512570 